\title{
IAHS/AGU Symposium on Groundwater Contamination
}

\section{LINDA M. ABRIOLA}

Environmental and Water Resources Engineering

The University of Michigan

Ann Arbor, Michigan 48109-2125, U.S.A.

JEAN M. BAHR

Department of Geology and Geophysics

University of Wisconsin

Madison, Wisconsin 53706, U.S.A.

ABSTRACT / Papers presented at a two-day jointly sponsored IAHS/AGU symposium on groundwater contamination are briefly summarized. This international symposium was held 11-12 May, 1989, in Baltimore, Maryland. Presentations encompassed recent research developments in three general areas: abiotic and biotic processes governing contaminant transport; aquifer rehabilitation; and the influence of agricultural practices and nonpoint sources on aquifer quality. Contributions offered an interesting mixture of theoretical, mathematical, laboratory, and field studies. In the first session, transport processes explored ranged from dispersion and fingering to nonequilibrium sorption, metals complexation, and bacteria migration. The use of optimization modeling in the design of remediation strategies was the focus of another session. Here theoretical studies were presented alongside case histories of aquifer rehabilitation. In a final session, a number of models for agricultural management were described. These presentations were complemented by case studies of actual aquifer degradation resulting from land-use and management practices.
A symposium on groundwater contamination was held on 11-12 May 1989, in Baltimore, Maryland, as part of the Third Scientific Assernbly of the International Association of Hydrological Sciences (IAHS). The sessions were jointly sponsored by IAHS and the American Geophysical Union (AGU) and were scheduled to overlap with the AGU spring meeting. Forty-two papers were presented over the two-day period, and session participants included IAHS members from some 12 nations as well as AGU members from many regions in North America. The symposium was divided into three consecutive topical sessions: (1) physical, chemical, and biological processes governing transport; (2) aquifer rehabilitation and case studies; and (3) aquifer degradation due to agricultural practices and nonpoint sources. L. M. Abriola (University of Michigan, Ann Arbor, Michigan) served as IAHS Convenor for the symposium.

The first session lasted a full day, and was attended by more than 150 people. This session was coorganized by J. M. Bahr (University of Wisconsin, Madison, Wisconsin). H. Rubin (Technion, Haifa, Israel) and V. Ramnarong (Department of Mineral Resources, Bangkok, Thailand) assisted as session moderators in the morning and afternoon sessions, respectively.

The morning session was devoted primarily to presentations involving physical processes governing transport. Papers encompassed a range of topics, dealing with theoretical and modeling studies as well as laboratory and field investigations. The first group of papers was concerned with exploration of the dispersion process. D. van Rooy, A. Keidser, and D. Rosbjerg (Technical University of Denmark, Lyngby,
Denmark) considered the determination of flow and transport parameters from head and concentration data by an objective function minimization approach. Based on their experience with a synthetic test problem, they concluded that concentration plume predictions were relatively insensitive to dispersion estimates and depended much more strongly on the source strength and the transmissivity field. Moreover, a good fit to the concentration plume at a particular time did not ensure reliable predictions beyond that time.

Two theoretical studies of dispersion were presented by R. L. Naff (U.S.G.S., Denver, Colorado) and by C. Welty (Drexel University, Philadelphia, Pennsylvania) and L. W. Gelhar (Massachusetts Institute of Technology, Cambridge, Massachusetts). Naff examined transport in a mean uniform flow field where hydraulic conductivity was represented as a stochastic process. No assumption was made concerning the stationarity of the concentration field. Welty and Gelhar examined the effects of density coupling between the flow and transport equations in a heterogeneous porous medium by the use of spectral methods. In the transient, one-dimensional case, macrodispersivity was found to depend on concentration and concentration gradient, resulting in a nonlinear mean solute transport equation. Density effects were found to have greater impact on macrodispersivity than viscosity effects.

D. Rathnayake (Bart-Gromer Associates, East Seattle, Washington) and H.J. Morel-Seytoux (Colorado State University, Fort Collins, Colorado) presented an approach to transport modeling that couples 
a coarse grid flow model solution with an interblock transport evaluation. Flow fields within a grid block were determined using a semianalytical approach. Macroscopic dispersive behavior was simulated without consideration of local dispersion.

A novel method employing fiberoptic fluorimetry to explore dispersive transport was presented by J. M. Nielsen (Environ Corp, Princeton, New Jersey), G. F. Pinder (Princeton University, Princeton, New Jersey), and T. J. Kulp (Lawrence Livermore National Laboratory, Livermore, California). By use of this approach, spatial variability in concentrations within laboratorypacked soil columns was examined at the pore scale.

Two experimental studies of solute transport at the field scale also were presented. W. R. Waldrop, J. M. Boggs, and S. C. Young (TVA Engineering Laboratory, Morris, Tennessee) reviewed progress on an Electric Power Research Institute-sponsored macrodispersion experiment (MADE), involving injection of nonreactive tracers in an alluvial aquifer at Columbus Air Force Base, Mississippi. The aquifer exhibits a large variance in hydraulic conductivity, and concentration measurements have not conformed to expectations. The plume appears to be extremely skewed in the longitudinal direction. At a site in Socorro, New Mexico, another field study is underway. B. D. Stephens, R. S. Bowman, K. Flanigan, D. Grabka, E. Mattson, and A. Parsons (New Mexico Tech, Socorro, New Mexico) gave an overview of this well-instrumented unsaturated zone transport experiment. Under constant infiltration, wetting front propagation was monitored by neutron logging and tensiometers and was found to be influenced strongly by site geology. Observations of conservative and nonconservative tracer migration are in progress. These measurements should provide a wealth of data for unsaturated zone modelers.

The morning session concluded with a number of papers involving multiphase flow and transport. In an experimental study, R. J. Glass (Sandia National Laboratories, Albuquerque, New Mexico), T. S. Steenhuis, J. Throop, J. Salker, and J.-Y. Parlange (Cornell University, Ithaca, New York) used back-illumination in conjunction with video-imaging technology to examine the development and propagation of fingers in unsaturated flow. The observations revealed that fingers tend to persist and remain as preferential conduits even after drainage and rewetting. Two papers pertaining to the modeling of multiphase organic chemical migration were presented. In the first, by A. Pistiner, H. Rubin, and M. Shapiro (Technion, Haifa, Israel), an analytical self-similar approach to the modeling of two-phase flow was discussed. The influence of fluid and matrix properties on organic-phase imbibition and drainage was examined. In a modeling study by J. J. Kaluarachchi, T. C. Parker, and R. J. Lenhard (Virginia Polytechnic Institute and State University, Blacksburg, Virginia) a three-phase flow model incorporating interphase mass transfer and hysteresis was employed to examine the impact of wetting reversals and fluid entrapment near the water table on the propagation of dissolved and volatilized constituents. M. M. McNeill, C. T. Miller, and A. S. Mayer (University of North Carolina, Chapel Hill, North Carolina) discussed recent results of laboratory experiments designed to examine the dependence of organic-water interphase mass transfer on system properties. The mass transfer coefficient was found to exhibit marked velocity dependence at low velocities. Cosolvent addition was demonstrated to enhance mass transfer.

The afternoon session included papers on biological and chemical processes. R. Harvey (U.S.G.S., Menlo Park, California) provided an overview of factors controlling the migration of bacteria in aquifers and compared results of two field experiments. In a sand and gravel aquifer on Cape Cod, bacteria breakthrough coincided with that of a bromide tracer. During a test conducted on Oahu, however, bacteria breakthrough preceded bromide, suggesting that size exclusion can restrict bacterial migration to preferential flow paths. Presentations by M. Y. Corapcioglu and M.A. Hossain (Washington State University, Pullman, Washington) and by E. O. Frind, E. A. Sudicky, and J.W. Molson (Waterloo Centre for Groundwater Research, Waterloo, Ontario) described numerical models for biodegradation of contaminants assuming an immobile microbial population. Corapcioglu and Hossain used their model to simulate anaerobic degradation of several chlorinated organics. Frind and others compared results of two-dimensional and three-dimensional simulations of aerobic degradation, concluding that proper treatment of dimensionality is required to obtain accurate predictions.

H. W. Olsen (U.S.G.S., Denver, Colorado) E. N. Yearsley and K. R. Nelson (Colorado School of Mines, Golden, Colorado) discussed three processes, chemical osmosis, electroosmosis and diffusion osmosis, that can induce groundwater flow in the absence of or counter to gradients in hydraulic potential. They presented laboratory experimental evidence for water movement accompanying solute diffusion. The direction of water movement during this diffusion osmosis is opposite to that expected for chemical osmosis through a semipermeable membrane.

Papers presented by L. Sovadina (Organization for 
Engineering Geology and Hydrogeology, Kosice, Czechoslovakia), by M. J. L. Robin, R. W. Gillham, and E. A. Sudicky (Waterloo Centre for Groundwater Research), by A. J. Valocchi and H. A. M. Quinodoz (University of Illinois, Urbana-Champaign, Illinois), and by M. L. Brusseau (University of Florida, Gainesville, Florida) and E. A. Sudicky investigated various aspects of modeling transport of exchanging or sorbing cations. Sovadina presented simulated breakthrough curves to illustrate the effects of initial and boundary conditions, hydrodynamic dispersion, and isotherm nonlinearity. Using over 1200 measurements of hydraulic conductivity and strontium distribution coefficients from samples obtained from the Borden site, Robin and others found only a weak correlation between the parameters for the aquifer as a whole. However, a more detailed analysis of the data yielded significant vertical trends and horizontal periodicity in sorption properties. Valocchi and Quinodoz used a random-walk model to investigate the relative importance of nonequilibrium sorption and aquifer heterogeneity on plume dispersion. Brusseau and Sudicky presented results of a numerical model that can account for multiple nonequilibrium processes including mass transfer between mobile and immobile phases, diffusion, and chemical kinetics.

The next three papers discussed interactions of inorganics and organics affecting the mobility of metals in groundwater. The model of F. Laszlo and F. Szekely (Research Centre for Water Resources Development, Budapest, Hungary, presented by G. Kienitz) accounts for a sequence of instantaneous redox reactions that affect mobility of iron and manganese. Batch experiments conducted by R. W. Plus and R. M. Powell (Kerr Environmental Research Laboratory, Ada, Oklahoma) indicated decreased sorption of lead in the presence of organic acids. This decrease in sorption could be the result of solution phase complexation or competition between the metal and organics for surface sites. The slow rate of organic sorption onto kaolinite observed during these experiments suggests that solution phase complexation is the more important process. D. B. Kent, J. A. Davis, B. A. Rea, A. S. Maest, and A. J. Roman-Mas (U.S.G.S., Menlo Park, California) reported results of three field experiments examining the mobility of chromium. Significant differences in retardation and immobilization of chromium were observed between the three experiments. These can be explained by variations in speciation and the extent of complexation with EDTA as a function of redox conditions and $\mathrm{pH}$ in the aquifer.

The final paper by G. S. M. van Meurs, J. Taat, D. Pereboom, F. Weststrate and M. Loxham (Delft Geo- technics, Delft, The Netherlands) compared results of one- and two-dimensional models and of models accounting for geochemical speciation and models incorporating an effective retardation factor. These comparisons indicate that breakthrough times and maximum concentrations predicted are sensitive to assumptions regarding flow field dimensionality and geochemical processes.

On the second day of the symposium, the morning session was devoted to papers dealing with aquifer rehabilitation methods. Theoretical modeling and field case studies were presented. Approximately 75 people attended this session. It was coorganized and moderated by L. Toran (Oak Ridge National Labs, Oak Ridge, Tennessee) and R. E. Jackson (Canada Centre for Inland Water, Burlington, Ontario).

One theme of the session was the flexible use of optimization modeling approaches to design hydraulic remediation strategies. D. P. Ahlfeld (University of Connecticut, Storrs, Connecticut) discussed how qualitative characteristics of the optimization model solution can provide insight into remediation design. He argued that reliance on model predictions for exact pumping rates is unwarranted and that subsequent adjustment of the remediation scheme based on field measured response may be required. R. Andricevic and P. K. Kitanidis (Stanford University, Stanford, California) presented a formal optimization methodology to account for parameter uncertainty in remediation design. The total cost to be minimized was viewed as the sum of two parts: one that depends on the best estimates of the parameters and one that increases with the error in this estimation. Another approach to incorporate parameter uncertainty was presented by T. Tucciarelli and G. Pinder (Princeton University, Princeton, New Jersey). Here a global minimization was sought for the sum of aquifer investigation and remediation costs. The position and number of new measurement locations were included in the model as decision variables.

Hydraulic remediation strategies also were modeled by C. Zheng, (S. S. Papadopulos and Associates, Rockville, Maryland), M. P. Anderson (University of Wisconsin, Madison, Wisconsin), and K. R. Bradbury (Wisconsin Geological Survey, Madison, Wisconsin). Here, however, the emphasis was on the deterministic assessment of the effectiveness of the selected strategy by the use of stream function and particle tracking modeling approaches. Steady-state and transient scenarios in two and three dimensions were explored.

Three papers were presented that described the use of hydraulic control measures at field sites. R. E. Jackson, A. S. Crowe, S. Lesage, and N. W. Priddle 
(Canada Centre for Inland Water, Burlington, Ontario) discussed the design of the purge-pump, treat, and recharge remediation strategy for an organic solvent-polluted glacial outwash aquifer near Ottawa. E. Fordham, E. L. Ambos, and M. A. Mooradian (Geo Research, Long Beach, California) described the design and installation of an interceptor trench network system to remove an extensive lens of perched gasoline-contaminated groundwater. Water was pumped to an air-stripping tower for treatment. G. A. Cederberg, C. M. Sorauf, and M. F. N. Mohsen (Environ Corporation, Princeton, New Jersey) presented a case study involving shallow and deep aquifer pollution by Volatile Organic Compounds (VOCs) and polychlorinated biphenyls. As with the previous case studies, contaminant strategy design was facilitated by a groundwater modeling program to assess the effectiveness of alternative approaches. In this situation, an extensive drain system was designed. Slurry walls were found useful to prevent migration of clean water to the drains.

Two papers in the session focused on some of the chemical aspects related to remediation design. M. J. Barcelona and T. R. Holm (State Water Survey, Champaign, Illinois) made extensive measurements of the oxidizing and reducing capacities of aquifer solids and groundwater samples in a sand and gravel aquifer. Results of this study suggest that the aquifer would offer considerable resistance to redox condition adjustment, a requirement for many remediation schemes. G. Kenoyer, J. Reese, and J. Seaberg (Wright State University, Dayton, Ohio) explored sorption of five common VOCs in laboratory batch and field injection experiments. Rates of sorption and desorption were found to be rapid, but there was no apparent correlation between organic carbon and VOC-soil partition coefficients, suggesting sorption to mineral surfaces may play a role and that existing $K_{d}$ prediction techniques may be inadequate.

A strategy for the containment of trench-disposal low-level radioactive wastes was presented by G. K. Jacobs and B. P. Spalding (Oak Ridge National Laboratory, Oak Ridge, Tennessee). Field demonstration results of an in situ vitrification experiment were discussed. Through this technique, the contaminated soil-waste mass is melted to form a glass-to-microcrystalline waste form. The method appears promising for the control of leaching of short half-life compounds from such trenches.

The final symposium session focused on aquifer degradation that results from agricultural practices and nonpoint sources. Session moderators included J. C. van Dam (Delft University, Pijnacker, The Neth- erlands) and S. Gorelick (Stanford University, Stanford, California). D. R. Nielsen (University of California, Davis, California) delivered a thought-provoking keynote address. This session was attended by some 50 people.

Nielsen's talk departed substantially from his IAHS conference proceedings paper, which is essentially an extensive review of approaches for the modeling of transport processes from the soil surface, through the unsaturated zone, to the groundwater. In his presentation, Nielsen focused instead on issues that modelers consistently tend to ignore or oversimplify. For example, water-quality and temperature effects on flow and transport properties of soils are customarily neglected even though they may have substantial impact. Nielsen suggested that the key to genuine improvement in our understanding of transport phenomena and our predictive capabilities lies in the development and encouragement of interdisciplinary education programs.

The keynote address was followed by a number of papers dealing with the development and use of transport models for agricultural management. G. Kienitz and J. Feher (Vituri, Budapest, Hungary) reported on work financed by the Hungarian Academy of Science, to construct a modular model to simulate physical, chemical, and biological processes in the soil root zone that impact water and nitrogen balances. Field data presently are being collected for model calibration. K. W. Rojas (U.S.D.A., Fort Collins, Colorado) and C. S. Hebson (R. G. Gerber, Inc., Freeport, Maine) described an Agricultural Research Service modular model being developed for unsaturated zone transport. The process-oriented model incorporates mass balances for water, nutrients, and pesticides. Some of the modeled processes include plant growth, organic water-nitrogen cycling, phosphorus adsorption, soil chemical equilibrium, and pesticide degradation and decay. The model has been implemented on microcomputers and example applications were presented. In a different type of study, J. C. Tracy and M. Marino (University of California, Davis, California) presented a two-dimensional simulator designed to investigate the influence of shallow aquifer gradients on transient salt distributions in the presence of tile drains. Simulation results showed that small gradients can seriously impact aquifer quality.

A final group of papers described case studies of aquifer degradation in various parts of the world. W. A. Flugel (Hydrological Research Institute, Pretoria, Republic of South Africa) presented a progress report on a research program designed to investigate groundwater contributions to the salinization of the 
Breede River. This catchment area is one of the most important agricultural production areas in South Africa. Groundwater discharge is implicated as a major contributor to water-quality deterioration. The study revealed that a considerable amount of salt applied with irrigation water is stored in the unsaturated zone during the irrigation season and subsequently leached to groundwater during winter rainfalls. D. R. Williamson, A. J. Peck, J. V. Turner (CSIRO, Wembley, Western Australia), and S. Arunin (Department of Land Development, Bangkok, Trailand) presented results of a salinization study in northeast Thailand. Here deforestation and development of nonirrigated agriculture was found to enhance groundwater recharge and cause dissolution of halite from existing evaporite beds. These conclusions were reached through intensive investigation and numerical modeling of the flow system. Proposed management schemes will be assessed with the use of the developed model. The impact of spreading manure and of acid rain on groundwater quality in the Netherlands was described by C. G. E. M. van Beek, F. A. M. Hettinga (Kiwa Ltd., Nieuwegein, The Netherlands) and R. Straatman (Water Supply Company "Oost Brabant," Hertogenbosch, The Netherlands). Shallow-well moni- toring networks and detailed chemical analyses were used to assess the pollution load and extent of waterquality deterioration. Heavy applications of manure and fertilizers coupled with atmospheric deposition of acids and metals resulted in high nitrate, zinc, sulfate, aluminum, and heavy-metal concentrations within the soil. J. Soveri (Water and Environment Research Institute, Helsinki, Finland) reported on a preliminary study to assess the impact of acid meltwater percolation on groundwater quality in Finland. Chemical processes within the unsaturated zone were investigated by the collection of percolation water from different soil horizons and by examining snow samples. The unsaturated zone was found to play a key role in the determination of groundwater quality.

Further information on the symposium presentations described briefly above may be obtained from two sources. Papers from the IAHS contributors have been published as "Ground Water Contamination," L. M. Abriola, ed., IAHS Publ. No. 185. This volume includes 22 papers and is available from IAHS Treasurer, 2000 Florida Ave., N.W, Washington, D.C. 20009 , for $\$ 40$. Abstracts of the remaining presentations can be found in Eos v. 70, no. 15, 1989. 